\title{
You, Me, and No One Else: Degree of Social Distancing and Personality Predict Psychological Wellness and Relationship Quality During the COVID-19 Pandemic
}

\author{
A. Bell Cooper ${ }^{1}$, Rachel E. Pauletti ${ }^{2}$, and Chloe' A. DiDonato ${ }^{2}$ \\ ${ }^{1}$ College of Business and Management, Lynn University \\ ${ }^{2}$ College of Arts and Sciences, Lynn University
}

\begin{abstract}
Author Note
We have no conflicts of interest to disclose.

Correspondence concerning this article should be addressed to A. Bell Cooper, College of Business and Management, Lynn University, Boca Raton, FL. Email: bcooper@1ynn.edu

A. Bell Cooper is an Assistant Professor of Quantitative Methods and Business Analytics at Lynn University's College of Business and Management. She specializes in personality, social psychology, and quantitative methods.

Rachel E. Pauletti is an Associate Professor of Psychology at Lynn University's College of Arts and Sciences. She specializes in personality and social development, with an emphasis on the self-concept.
\end{abstract}

Chloe' A. DiDonato is a 2019 graduate of Lynn University. She holds a B.A. in Psychology. 


\begin{abstract}
While incredibly disruptive to everyday life, the COVID-19 pandemic provides a unique opportunity to study the influence of social distancing and quarantine behaviors on mental health and relationship quality. In this study, we used a snowball sample of 519 Americans to examine whether there were relationships between personality, degree of adherence to social distancing and quarantining norms and regulations, and psychological wellness and relationship quality. We discovered several interesting patterns, some more intuitive than others. Specifically, we present evidence of several interactive effects between personality and degree of social distancing predicting psychological wellness and relationship quality with cohabitants, indicating that some people may fare better in quarantine than others. Results are discussed in terms of practical applications and may provide helpful insights to policymakers and personality psychologists alike.
\end{abstract}

Keywords: COVID-19, Personality, Psychological Wellness, Relationship Quality, Mental health, Big Five 


\section{You, Me, and No One Else: Degree of Social Distancing and Personality Predict Psychological Wellness and Relationship Quality During the COVID-19 Pandemic}

The rapid worldwide spread of COVID-19, the disease stemming from SARS-CoV-2, has led to disruption of daily lives worldwide. The combination of uncertain transmissibility and the lack of a vaccine has led to varied, and often confusing, governmental regulations for quarantining and social distancing (henceforth, collectively referred to as social distancing). (For variance in regulations across the United States, see the National Conference of State Legislatures, 2020). This has led to drastic individual differences in compliance to the regulations (Imhoff \& Lamberty, 2020). One major concern is the impact of social distancing on psychological wellness (Mazza et al., 2020; Zhang et al., 2020). There is evidence that situational features, such as measures taken by the government, are related to levels of psychological wellness (Qui et al., 2020), and the novelty of this event invites understanding of individual differences in how people cope with the pandemic.

This study sought to explore individual differences in coping with the pandemic in the United States. We sought to answer three questions.

\section{Question 1: Does personality affect social distancing behavior?}

Given that personality has a large effect on everyday behavior (Jones et al., 2017; Sherman et al., 2015), and particularly on cooperation (e.g. Kagel \& McGee, 2014) and health behaviors (e.g. Booth-Kewley \& Vickers, 1994; Friedman \& Booth-Kewley, 1987), we expected that personality will play a role in social distancing behaviors. Some early evidence suggests that personality plays a role in behavior related to the COVID-19 pandemic, such as stockpiling toilet paper (Garbe, 2020) and social distancing behavior (Modersitzki et al., 2020). In the current study, we assessed personality using Big Five dimensions (Goldberg, 1990). Based on the Big 
Five construct definitions and previous research, we specifically expected that agreeableness, conscientiousness, neuroticism, and openness would be related to more extreme social distancing behaviors (i.e. more physical distancing and isolation such as quarantining), and that extraversion would be related to less extreme behaviors.

\section{Question 2: How does the degree of social distancing affect psychological wellness and} relationship quality with cohabitants?

Social distancing, whether mandated or voluntary, has made it difficult to maintain social contact with friends, family, and coworkers. Extreme social isolation can lead to severe mental health outcomes, whether the isolation is objective (e.g., prisoners in solitary confinement; Grassian, 1983), or subjective (i.e., the extent to which an individual feels isolated; Cacioppo \& Cacioppo, 2014). Individuals who cohabitate with others may rely more on those relationships to cope with feelings of isolation (Okabe-Miyamoto et al., 2020). But it is unclear how psychological wellness and relationship quality are impacted by social distancing due to the pandemic. We sought to explore the association between degree of social distancing and psychological wellness or relationship quality with cohabitants. We expected that longer periods and more extreme social distancing would negatively impact overall psychological wellness. We assess psychological wellness in terms of daily affect, subjective well-being, and life satisfaction. Due to limited research on relationships with cohabitants during a pandemic, we had no prior hypotheses for relationship quality.

Question 3: Does personality moderate the association between degree of social distancing and psychological wellness or relationship quality?

No known studies have examined how personality moderates the association of social distancing and psychological wellness or relationship quality during a pandemic. Given the 
evidence that personality is a predictor of behavior (Modersitzki et al., 2020), psychological wellness (Costa \& McCrae, 1980; Shimmack et al., 2004), and relationship quality (Holland \& Roisman, 2008), we sought to examine the interactive effects of personality and degree of social distancing on these outcomes. We had a few general hypotheses.

(1) We expected an exacerbating interactive effect of extraversion on the association between degree of social distancing and psychological wellness. Given that higher degree of social distancing is likely more restrictive in terms of social interactions with others, we expected that those higher in extraversion would experience more damaging effects to psychological wellness as they experienced higher degrees of social distancing, and vice versa for low extraversion individuals.

(2) We expected an interactive effect between conscientiousness and degree of social distancing on psychological wellness. We hypothesized that as degree of social distancing increased, higher conscientiousness would predict lower psychological wellness. We reasoned that high conscientious individuals would struggle with the limitations of high degrees of social distancing, such as less access to resources, inability to perform important tasks, and distractions by cohabitants, and vice versa for low conscientious individuals.

(3) We expected an interactive effect between neuroticism and degree of social distancing on psychological wellness. We reasoned that those higher in neuroticism would feel more comfortable with the protective boundaries of a higher degree of social distancing, thus resulting in higher psychological wellness, and that those lower in neuroticism would be frustrated by those same boundaries and limitations, resulting in lower psychological wellness. 
We had no other hypotheses for the interactive effects of personality and degree of social distancing on psychological wellness, and we performed exploratory analyses for all predictors and outcomes. In terms of relationship quality, we had no a priori hypotheses, and we performed exploratory analyses for all predictors and outcomes.

\section{Method}

\section{Participants}

Participants were recruited exclusively in the United States through a snowball sample on social media outlets. The authors advertised for the study through Facebook, Instagram, LinkedIn, email, and text message, and then requested that each interested individual advertise on their own networks. Individuals who completed the study were automatically entered to win a \$50 Amazon gift card. Six hundred and fifty-three participants completed the survey, and of those, 516 were considered valid respondents based on complete and correct responses to six validity questions (e.g. "Please select '4' for this item.”) randomly placed throughout the survey (Ethnicity: 12.45\% African American/Black, 6.61\% Asian/Pacific Islander, 68.29 Caucasian/White, 9.14\% Hispanic/Latino, .97\% Native American/American Indian, 2.14\% Other, .49\% No Response; Gender: $21.88 \%$ Male, $78.73 \%$ Female; Ages 18 to $85, M=35.42$, Median = 31). IP Addresses reflected respondents from 38 out of 50 states in the United States. Participants responded in April through June of 2020. The final sample size exceeds the size needed to generalize to the population of the United States with a $95 \%$ confidence level and a confidence interval of $5 \%$.

\section{Measures}

\section{Personality}


Personality was assessed using the Big Five Inventory-10 (BFI-10: Rammstedt \& John, 2007). The BFI-10 contains 10 items assessing each of the Big Five dimensions: extraversion $(\mathrm{X})$, agreeableness (A), conscientiousness $(\mathrm{C})$, neuroticism $(\mathrm{N})$, and openness $(\mathrm{O})$. Responses were assessed on a scale of 1 (Strongly disagree) to 5 (Strongly agree).

\section{Degree of Social Distancing}

Degree of social distancing was measured in multiple ways: social participation, days in quarantine, and days in social distancing, and magnitude of social distancing behavior. For all descriptive statistics, see Table 1. 
Table 1

Descriptive Statistics of All Variables

\begin{tabular}{|c|c|c|c|}
\hline \multicolumn{4}{|c|}{ Degree of Social Distancing } \\
\hline & $\mathbf{N}$ & $\mathbf{M}$ & SD \\
\hline In-Person Activities Total & 503 & 10.44 & 12.19 \\
\hline Class/lecture/meeting & 512 & .28 & 1.02 \\
\hline Religious service & 512 & .09 & .63 \\
\hline Crowd of 10 or more & 512 & .27 & .91 \\
\hline Music or TV with others & 507 & 6.44 & 10.41 \\
\hline Run errands & 510 & 1.74 & 1.82 \\
\hline Physical exercise & 511 & 1.39 & 2.23 \\
\hline Ride, picnic, parties & 510 & .40 & 1.11 \\
\hline Competitive/team sport & 512 & .06 & .60 \\
\hline Visit friends & 512 & .56 & 1.29 \\
\hline Visit relatives & 512 & .62 & 1.39 \\
\hline Online Activities Total & 507 & 9.39 & 11.61 \\
\hline Virtual chat & 511 & 5.06 & 5.6 \\
\hline Virtual chat for work/school & 508 & 4.29 & 8.53 \\
\hline Reading or watching news & 506 & 8.66 & 14.96 \\
\hline Social media & 502 & 16.95 & 37.7 \\
\hline $\begin{array}{l}\text { Magnitude of Social } \\
\text { Distancing Behavior }\end{array}$ & 515 & 3.90 & .75 \\
\hline Days in Quarantine & 297 & 29.54 & 14.90 \\
\hline Days in Social Distancing & 398 & 30.88 & 14.80 \\
\hline Relative to Normal Routine & $\mathbf{N}$ & $\mathbf{M}$ & SD \\
\hline $\begin{array}{c}\text { Average In-Person } \\
\text { Activities }\end{array}$ & 495 & 2.11 & .50 \\
\hline Class/lecture/meeting & 506 & 1.62 & .90 \\
\hline Religious service & 506 & 2.28 & .92 \\
\hline Crowd of 10 or more & 507 & 1.52 & .73 \\
\hline Music or TV with others & 511 & 3.19 & 1.13 \\
\hline Run errands & 508 & 1.94 & .96 \\
\hline Physical exercise & 507 & 2.41 & 1.09 \\
\hline Ride, picnic, parties & 506 & 1.87 & .88 \\
\hline Competitive/team sport & 505 & 2.45 & .89 \\
\hline Visit friends & 508 & 1.77 & .87 \\
\hline Visit relatives & 510 & 2.00 & .95 \\
\hline Average Online Activities & 499 & 3.91 & .87 \\
\hline Virtual chat & 507 & 4.04 & .94 \\
\hline Virtual chat for work/school & 504 & 3.79 & 1.05 \\
\hline Reading or watching news & 509 & 3.66 & .93 \\
\hline Social media & 512 & 3.81 & .95 \\
\hline
\end{tabular}

\begin{tabular}{|c|c|c|c|c|}
\hline \multicolumn{4}{|c|}{ Psychological Wellness } & \\
\hline & N & M & SD & $\boldsymbol{\alpha}$ \\
\hline Positive Affect & 515 & 3.06 & .94 & .85 \\
\hline Calm & 516 & 3.20 & 1.11 & \\
\hline Well-Being & 516 & 3.27 & 1.03 & \\
\hline Vigor & 515 & 2.71 & 1.07 & \\
\hline Negative Affect & 512 & 2.80 & 1.04 & .84 \\
\hline Anger & 513 & 2.27 & 1.18 & \\
\hline Anxiety & 514 & 2.88 & 1.29 & \\
\hline Depression & 514 & 2.72 & 1.29 & \\
\hline Fatigue & 513 & 3.35 & 1.27 & \\
\hline Life Satisfaction & 516 & 3.47 & .71 & .85 \\
\hline
\end{tabular}

\begin{tabular}{|c|c|c|c|c|}
\hline \multicolumn{4}{|c|}{ Relationship Quality } & \\
\hline & $\mathrm{N}$ & $\mathrm{M}$ & SD & \\
\hline Spouse & 279 & 4.3 & 1.00 & \\
\hline Spouse - Comp. & 279 & 3.09 & .79 & \\
\hline Children & 132 & 4.24 & .93 & \\
\hline Children - Comp. & 132 & 3.1 & .89 & \\
\hline Family & 143 & 4.03 & .96 & \\
\hline Family - Comp. & 143 & 3.21 & .85 & \\
\hline In-Laws & 18 & 4.22 & .88 & \\
\hline In-Laws - Comp. & 18 & 2.94 & .87 & \\
\hline Roommate & 47 & 3.85 & 1.02 & \\
\hline $\begin{array}{l}\text { Roommate - } \\
\text { Comp. }\end{array}$ & 47 & 3.11 & .76 & \\
\hline
\end{tabular}

\begin{tabular}{|c|c|c|c|c|}
\hline \multicolumn{4}{|c|}{ Personality } & \\
\hline & $\mathrm{N}$ & $\mathrm{M}$ & $\mathrm{SD}$ & \\
\hline Extraversion & 515 & 3.21 & .90 & .57 \\
\hline Agreeableness & 515 & 3.56 & .72 & .27 \\
\hline Conscientiousness & 516 & 3.75 & .74 & .38 \\
\hline Neuroticism & 516 & 2.92 & .94 & .59 \\
\hline Openness & 516 & 3.59 & .83 & .30 \\
\hline
\end{tabular}


Social participation was adapted from the Social Participation Measure in Carnegie Mellon University's Common Cold Project (CCP: Laboratory for the Study of Stress, Immunity, and Disease, 2016). Participants were first asked the total number of times in the past week they have completed a variety of in-person and online social activities. Then, they were asked to rate on a scale of 1 (Far less than usual) to 5 (Far more than usual) how often they have done each of those things during the past week relative to their normal routines. For each person, we also aggregated their responses to create an In-Person Activities Total by summing all of their inperson activities, and an Online Activities Total by summing their virtual chat and virtual chat for work/school scores. We averaged the same individual scores to form two aggregate Relative to Normal Routine scores for Average In-Person Activities and Average Online Activities.

Days in quarantine and days in social distancing were assessed by first asking the question "Are you currently engaged in any of the following?" The options were "Quarantine or isolation (i.e., are you situated in the same place, with minimal or no contact physical contact with other people, either voluntarily or mandated by a medical or governmental figure?)," "Social distancing (i.e., are you minimizing your exposure to large groups of people and avoiding scenarios in which you may be exposed to other people)," and "None of the above." For individuals who selected either or both of the first two options, they were then asked how many days they had been engaged in each. Approximately $7.36 \%$ of participants marked that they were involved in just quarantine or isolation, $37 \%$ marked that they were involved in just social distancing, 53.29\% marked that they were involved in both quarantine and social distancing, and $1.94 \%$ marked "None of the above." Participants were also asked the reason(s) that they are currently engaged in quarantine or social distancing. The responses were divided into Mandated (such as by a medical professional or government official; $13.68 \%$ for quarantine, $8.56 \%$ for 
social distancing), Voluntary (to keep oneself or one's family/friends safe, because one felt it was their duty to do so, because of symptoms or exposure to COVID-19; $59.28 \%$ for quarantine, $82.01 \%$ for social distancing), or Mixed (27.04\% for quarantine, $9.42 \%$ for social distancing).

Magnitude of social distancing behavior was measured as an alternative way to examine the intensity of quarantine and social distancing in case participants had a different understanding of the definitions of each. It was assessed by following question: "Which of the following best describes your current behavior?" Options were considered on a scale of 1-5, with 5 indicating the highest degree of social distancing. The items were: (1) "I am continuing to socialize in public places," (2) "I am continuing to socialize in public places, but slightly less than before," (3) "I am not going to public places, but I am socializing with friends or family in my or their homes," (4) "I am not going to public places, but I am socializing with my friends or family virtually," and (5) "I am not going to public places, nor I am socializing with family or friends."

\section{Psychological Wellness}

Psychological wellness was measured in two ways. The first was a measure of daily affect adapted from the CCP's measure, Daily Affect in Quarantine (Laboratory for the Study of Stress, Immunity, and Disease, 2016). Participants were asked, "On a scale of 1 to 5, 1 being "haven't felt that way at all" and 5 being "have felt that way a lot," describe how you have been feeling for the last 48 hours." Items were aggregated up to two main affective variables positive and negative affect. Positive affect included calm ("calm, at ease, relaxed"), well-being ("happy, cheerful, pleased"), and vigor ("full of pep, lively, energetic"). Negative affect included anger ("hostile, angry, resentful"), anxiety (“on edge, tense, nervous”), depression (“sad, unhappy, depressed”), and fatigue (“tired, fatigued, sluggish, sleepy”). 
The second measure of psychological wellness was life satisfaction. Life satisfaction was assessed by using all five items from the Satisfaction with Life Scale (Diener, Emmons, Larsen, \& Griffin, 1985) plus two items from the Subjective Happiness Scale (Lyubomirsky \& Lepper, 1999). These items were "In general, I consider myself a very happy person," and "Compared to most of my peers, I consider myself happier than my peers.” All items were rated on a scale of 1 (“Strongly Disagree”) to 5 (“Strongly Agree”).

\section{Relationship Quality with Cohabitants}

To assess relationship quality with cohabitants, participants were first asked, "Which of the following people currently live in your household (not including yourself). Check all that apply." The options were "Your spouse/relationship partner," "Your children," "Your other family members (siblings, parents, etc.)," "Your partner's family members (your partner's siblings, parents, etc.)," "Roommate," and "Other." Then, for each option they selected, participants were asked two questions: "On a scale of 1 (Bad, miserable, unpleasant) to 5 (Good, enjoyable, pleasant), how would you describe the quality of your relationship(s) with your in the last week?" and "How would you rate the quality of your relationship with your ___ compared to usual?" The options for the latter question were rated on a scale of 1-5 with the anchors 1 (Much worse than usual), 3 (About the same as usual), and 5 (Much better than usual). For the category "Other," 31 out of 35 people designated that they live alone. Therefore, the "Other" category was excluded from further analyses.

\section{Results}

\section{Personality and Degree of Social Distancing}

All data, R scripts, and measures are available online at XXXX. Table 2 displays the correlations between personality and degree of social distancing. It should be noted that the 
shortened measure for personality and the low internal consistency may contribute to diminished effect sizes. Therefore, we focus mainly on trends of findings rather than narrowing in on specific individual relationships. We found a trend of small positive correlations between extraversion and social participation, both in-person and online. Relative to normal routine, extraversion was negatively correlated with in-person activities and positively correlated with online activities. Conscientiousness showed a trend of negative correlations with in-person social participation, but was positively related to online social participation, both relative to peers and relative to normal routine. Neuroticism showed a trend of negative correlations with in-person social participation relative to peers, and little-to-no effects otherwise. Neuroticism was also negatively correlated with reading or watching the news, both relative to peers and relative to normal routine. Agreeableness correlated negatively with in-person social participation and positively with online social participation. Openness showed little-to-no effects on social participation. 
Table 2

Degree of Social Distancing Correlations with Big Five and Daily Affect

\begin{tabular}{|c|c|c|c|c|c|c|c|c|}
\hline & $\begin{array}{c}\text { Positive } \\
\text { Affect }\end{array}$ & $\begin{array}{c}\text { Negative } \\
\text { Affect }\end{array}$ & $\begin{array}{c}\text { Life } \\
\text { Satisfaction }\end{array}$ & $\mathbf{X}$ & A & $\mathbf{C}$ & $\mathbf{N}$ & $\mathbf{O}$ \\
\hline & $\mathrm{r}(\mathrm{p})$ & $\mathrm{r}(\mathrm{p})$ & $\mathrm{r}(\mathrm{p})$ & $\mathrm{r}(\mathrm{p})$ & $\mathrm{r}(\mathrm{p})$ & $\mathrm{r}(\mathrm{p})$ & $\mathrm{r}(\mathrm{p})$ & $\mathrm{r}(\mathrm{p})$ \\
\hline $\begin{array}{c}\text { In-Person Activities } \\
\text { Total }\end{array}$ & $.10(.023)$ & $-.06(.190)$ & $-.04(.350)$ & $.04(.433)$ & $-.01(.845)$ & $-.03(.437)$ & $-.08(.061)$ & $.01(.865)$ \\
\hline Class/lecture/meeting & $.06(.146)$ & $-.04(.419)$ & $.07(.126)$ & $.04(.424)$ & $.05(.216)$ & $.05(.233)$ & $-.04(.330)$ & $.01(.859)$ \\
\hline \begin{tabular}{|l|} 
Religious service \\
\end{tabular} & $.08(.070)$ & $-.15(\mathrm{p}<.001)$ & $-.12(.009)$ & $.04(.421)$ & $-.09(.044)$ & $-.01(.877)$ & $-.04(.379)$ & $-.07(.114)$ \\
\hline Crowd of 10 or more & $.06(.181)$ & $.00(.914)$ & $-.05(.275)$ & $.00(.952)$ & $-.02(.713)$ & $.00(.917)$ & $-.03(.451)$ & $-.03(.516)$ \\
\hline \begin{tabular}{|c|}
$\begin{array}{c}\text { Music or TV with } \\
\text { others }\end{array}$ \\
\end{tabular} & $.09(.040)$ & $-.11(.016)$ & $-.05(.227)$ & $.02(.611)$ & $.02(.618)$ & $-.02(.716)$ & $-.07(.139)$ & $.04(.368)$ \\
\hline Run errands & $.09(.040)$ & $-.11(.016)$ & $-.05(.227)$ & $.03(.451)$ & $.00(.967)$ & $.02(.644)$ & $-.10(.020)$ & $-.05(.273)$ \\
\hline Physical exercise & $.15(\mathrm{p}<.001$ & $-.11(.010)$ & $.09(.048)$ & $-.02(.700)$ & $.05(.228)$ & $.08(.073)$ & $-.10(.030)$ & $-.01(.775)$ \\
\hline Ride, picnic, parties & $.08(.056)$ & $-.04(.315)$ & $-.06(.146)$ & $.02(.639)$ & $.00(.912)$ & $-.05(.239)$ & $.02(.707)$ & $-.04(.388)$ \\
\hline $\begin{array}{c}\text { Competitive/team } \\
\text { sport }\end{array}$ & $.08(.083)$ & $-.05(.282)$ & $-.08(.087)$ & $-.05(.267)$ & $-.07(.115)$ & $-.08(.073)$ & $.00(.977)$ & $-.03(.538)$ \\
\hline Visit friends & $.13(.003)$ & $-.10(.025)$ & $-.07(.137)$ & $.03(.502)$ & $-.10(.026)$ & $-.04(.321)$ & $-.10(.028)$ & $-.08(.083)$ \\
\hline Visit relatives & $.08(.088)$ & $-.08(.067)$ & $-.08(.064)$ & $.02(.668)$ & $-.01(.778)$ & $-.04(.425)$ & $.02(.650)$ & $-.05(.230)$ \\
\hline $\begin{array}{c}\text { Online Activities } \\
\text { Total }\end{array}$ & $.03(.433)$ & $-.01(.897)$ & $.05(.219)$ & $.09(.049)$ & $.02(.594)$ & $.18(\mathrm{p}<.001)$ & $-.02(.633)$ & $.00(.963)$ \\
\hline Virtual chat & $.08(.069)$ & $-.01(.762)$ & $.03(.500)$ & $.10(.024)$ & $.03(.541)$ & $.12(.006)$ & $-.03(.488)$ & $.07(.138)$ \\
\hline $\begin{array}{c}\text { Virtual chat for } \\
\text { work/school }\end{array}$ & $-.01(.859)$ & $.00(.984)$ & $.05(.232)$ & $.05(.230)$ & $.01(.749)$ & $.17(\mathrm{p}<.001)$ & $-.01(.857)$ & $-.05(.261)$ \\
\hline $\begin{array}{c}\text { Reading or watching } \\
\text { news }\end{array}$ & $-.03(.448)$ & $-.04(.389)$ & $.00(.977)$ & $-.02(.606)$ & $.03(.462)$ & $.07(.126)$ & $-.09(.037)$ & $-.05(.284)$ \\
\hline \begin{tabular}{|l|} 
Social media \\
\end{tabular} & $.01(.832)$ & $.01(.901)$ & $-.03(.568)$ & $.01(.783)$ & $-.01(.889)$ & $.01(.780)$ & $.01(.906)$ & $.02(.698)$ \\
\hline \begin{tabular}{|c|}
$\begin{array}{c}\text { Relative to Normal } \\
\text { Routine }\end{array}$ \\
\end{tabular} & $\begin{array}{c}\text { Positive } \\
\text { Affect }\end{array}$ & $\begin{array}{c}\text { Negative } \\
\text { Affect }\end{array}$ & $\begin{array}{c}\text { Life } \\
\text { Satisfaction } \\
\end{array}$ & $\mathbf{X}$ & A & $\mathbf{C}$ & $\mathbf{N}$ & $\mathbf{O}$ \\
\hline \begin{tabular}{|c|} 
Average In-Person \\
Activities
\end{tabular} & $-.02(.708)$ & $.06(.167)$ & $-.09(.037)$ & $-.08(.079)$ & $-.09(.048)$ & $-.08(.076)$ & $.06(.194)$ & $.02(.729)$ \\
\hline Class/lecture/meeting & $.06(.146)$ & $-.04(.419)$ & $.07(.126)$ & $.04(.397)$ & $-.01(.788)$ & $-.01(.829)$ & $.01(.895)$ & $.03(.490)$ \\
\hline \begin{tabular}{|c|} 
Religious service \\
\end{tabular} & $.08(.070)$ & $-.15(\mathrm{p}<.001)$ & $-.12(.009)$ & $.06(.194)$ & $-.01(.853)$ & $-.02(.736)$ & $.05(.308)$ & $.09(.053)$ \\
\hline Crowd of 10 or more & $.06(.181)$ & $.00(.914)$ & $-.05(.275)$ & $-.17(\mathrm{p}<.001)$ & $-.09(.045)$ & $-.05(.267)$ & $.04(.318)$ & $.00(.976)$ \\
\hline $\begin{array}{c}\begin{array}{c}\text { Music or TV with } \\
\text { others }\end{array} \\
\end{array}$ & $.09(.040)$ & $-.11(.016)$ & $-.05(.227)$ & $.03(.459)$ & $-.03(.479)$ & $.05(.287)$ & $.00(.972)$ & $-.01(.828)$ \\
\hline Run errands & $.09(.040)$ & $-.11(.016)$ & $-.05(.227)$ & $-.10(.019)$ & $-.04(.403)$ & $-.16(p<.001)$ & $-.01(.838)$ & $-.03(.447)$ \\
\hline Physical exercise & $.15(\mathrm{p}<.001$ & $-.11(.010)$ & $.09(.048)$ & $-.04(.383)$ & $-.03(.499)$ & $.00(.972)$ & $.00(.930)$ & $-.04(.392)$ \\
\hline Ride, picnic, parties & $.08(.056)$ & $-.04(.315)$ & $-.06(.146)$ & $-.10(.031)$ & $-.09(.033)$ & $-.03(.441)$ & $.05(.297)$ & $-.02(.581)$ \\
\hline $\begin{array}{c}\text { Competitive/team } \\
\text { sport }\end{array}$ & $.08(.083)$ & $-.05(.282)$ & $-.08(.087)$ & $-.01(.791)$ & $-.01(.747)$ & $.02(.605)$ & $.11(.014)$ & $.08(.069)$ \\
\hline Visit friends & $.13(.003)$ & $-.10(.025)$ & $-.07(.137)$ & $-.17(\mathrm{p}<.001)$ & $-.06(.157)$ & $-.11(.012)$ & $.03(.445)$ & $-.01(.771)$ \\
\hline Visit relatives & $.08(.088)$ & $-.08(.067)$ & $-.08(.064)$ & $-.05(.300)$ & $-.11(.014)$ & $-.10(.021)$ & $.04(.402)$ & $-.02(.657)$ \\
\hline $\begin{array}{c}\text { Average Online } \\
\text { Activities } \\
\end{array}$ & $-.06(.175)$ & $.02(.633)$ & $.13(.005)$ & $.15(\mathrm{p}<.001)$ & $.04(.404)$ & $.12(.007)$ & $-.03(.455)$ & $.00(.983)$ \\
\hline Virtual chat & $.08(.069)$ & $-.01(.762)$ & $.03(.500)$ & $.16(\mathrm{p}<.001)$ & $.05(.231)$ & $.12(.005)$ & $-.02(.613)$ & $.03(.519)$ \\
\hline \begin{tabular}{|c|}
$\begin{array}{c}\text { Virtual chat for } \\
\text { work/school }\end{array}$ \\
\end{tabular} & $-.01(.859)$ & $.00(.984)$ & $.05(.232)$ & $.09(.039)$ & $.02(.676)$ & $.10(.025)$ & $-.04(.372)$ & $-.03(.485)$ \\
\hline $\begin{array}{c}\text { Reading or watching } \\
\text { news }\end{array}$ & $-.03(.448)$ & $-.04(.389)$ & $.00(.977)$ & $.06(.190)$ & $-.01(.808)$ & $.06(.170)$ & $-.04(.421)$ & $-.10(.025)$ \\
\hline \begin{tabular}{|l|} 
Social media \\
\end{tabular} & $.01(.832)$ & $.01(.901)$ & $-.03(.568)$ & $.11(.012)$ & $.02(.695)$ & $.07(.100)$ & $.01(.811)$ & $-.02(.725)$ \\
\hline \begin{tabular}{|l|} 
Magnitude of Social \\
Distancing Behavior
\end{tabular} & $-.10(.020)$ & $.06(.186)$ & $.02(.582)$ & $.01(.838)$ & $.00(.913)$ & $.11(.010)$ & $.02(.629)$ & $.09(.036)$ \\
\hline Days in Quarantine & $.01(.837)$ & $-.05(.394)$ & $-.07(.221)$ & $-.07(.208)$ & $-.02(.697)$ & $-.07(.204)$ & $.12(.032)$ & $.04(.531)$ \\
\hline \begin{tabular}{|c|}
$\begin{array}{c}\text { Days in Social } \\
\text { Distancing }\end{array}$ \\
\end{tabular} & $-.02(.681)$ & $-.08(.128)$ & $.01(.902)$ & $-.02(.655)$ & $-.01(.804)$ & $.03(.493)$ & $.05(.338)$ & $.05(.341)$ \\
\hline
\end{tabular}

Note: $r=$ Pearson correlation coefficient. For Days in Quarantine, $n=297$. For Days in Social Distancing, $n=398$. For all other variables, $\mathrm{n}$ ranges from 494 to 515 due to some missing data. "Total" = Sum of activity count for each activity included in category for the past week. "Relative to normal routine" = Participants responded on a scale of (1) Far less than usual to (5) Far more than usual. 
In terms of the remaining variables measuring degree of social distancing, extraversion and conscientiousness were negatively correlated with days in quarantine and neuroticism was positively correlated with days in quarantine. Almost no effects were found for personality's association with days in social distancing. Conscientiousness and openness were positively correlated with magnitude of social distancing behavior.

\section{Degree of Social Distancing and Psychological Wellness}

To identify associations between degree of social distancing and psychological wellness, we performed one correlation between each measure of degree of social distancing and positive/negative daily affect or life satisfaction. Results are displayed in Table 2. We found a trend of positive correlations between in-person social participation and daily positive affect and a trend of negative correlations with daily negative affect. That is, as an individual participated in fewer in-person activities, their positive daily affect was lower, and their negative daily affect was higher. Specifically, the strongest effects were found in attendance at religious services, running errands, physical exercise with others, and visits with friends and family. Interestingly, we found some opposing trends for the association between in-person activities and life satisfaction.

When asked about the frequency of social participation relative to their normal routine, we found a trend of negative correlations between in-person activities and positive affect and life satisfaction, and a trend of positive correlations between online activities and positive affect and life satisfaction. This suggests that any disruption of in-person routine results in worse affective outcomes, but an increase of online activities relates to better affective outcomes. 
In terms of length of time and magnitude of social distancing behavior, effects were quite small. The strongest effect was a negative correlation between magnitude of social distancing behavior and positive affect.

\section{Degree of Social Distancing and Relationship Quality with Cohabitants}

To identify associations between degree of social distancing and relationship quality with cohabitants, we performed one correlation between each measure of degree of social distancing (except for social participation) and each measure of relationship quality. See Table 3 for results.

Table 3

Big Five Correlations with and Relationship Quality with Cohabitants

\begin{tabular}{|c|c|c|c|c|c|c|c|c|}
\hline & $\mathrm{X}$ & A & $\mathrm{C}$ & $\mathrm{N}$ & $\mathrm{O}$ & $\begin{array}{l}\text { Magnitude } \\
\text { of Social } \\
\text { Distancing } \\
\text { Behavior } \\
\end{array}$ & $\begin{array}{c}\text { Days in } \\
\text { Quarantine }\end{array}$ & $\begin{array}{c}\text { Days in } \\
\text { Social } \\
\text { Distancing }\end{array}$ \\
\hline Relationship Quality & $\mathrm{r}(\mathrm{p})$ & $r(p)$ & $r(p)$ & $\mathrm{r}(\mathrm{p})$ & $\mathrm{r}(\mathrm{p})$ & $r(p)$ & $\mathrm{r}(\mathrm{p})$ & $r(p)$ \\
\hline Spouse & $.01(.820)$ & $.15(.011)$ & $.07(.258)$ & $-.15(.015)$ & $.09(.142)$ & $.15(.011)$ & $.03(.722)$ & $.04(.583)$ \\
\hline Spouse - Comp. & $-.05(.407)$ & $.12(.046)$ & $.05(.451)$ & $-.07(.275)$ & $-.02(.704)$ & $.07(.226)$ & $.19(.022)$ & $.08(.239)$ \\
\hline Children & $-.14(.102)$ & $.14(.115)$ & $.13(.141)$ & $-.22(.013)$ & $-.04(.623)$ & $-.02(.837)$ & $.14(.263)$ & $.16(.129)$ \\
\hline Children - Comp. & $-.11(.214)$ & $.07(.407)$ & $.08(.388)$ & $-.11(.222)$ & $-.09(.289)$ & $-.20(.020)$ & $.09(.455)$ & $.24(.016)$ \\
\hline Family & $.02(.800)$ & $.16(.061)$ & $.05(.559)$ & $-.35(\mathrm{p}<.001)$ & $-.10(.228)$ & $.02(.772)$ & $.24(.021)$ & $.11(.242)$ \\
\hline Family - Comp. & $.08(.342)$ & $.05(.532)$ & $-.02(.813)$ & $-.09(.261)$ & $-.06(.467)$ & $-.02(.812)$ & $.18(.085)$ & $.10(.283)$ \\
\hline In-Laws & $-.10(.703)$ & $-.29(.241)$ & $-.30(.225)$ & $-.14(.571)$ & $-.03(.896)$ & $-.27(.277)$ & $.30(.342)$ & $.19(.455)$ \\
\hline In-Laws - Comp. & $-.33(.188)$ & $-.15(.562)$ & $-.04(.882)$ & $-.06(.819)$ & $.23(.352)$ & $-.10(.696)$ & $.09(.775)$ & $.22(.404)$ \\
\hline Roommate & $-.07(.628)$ & $.07(.652)$ & $.20(.188)$ & $-.29(.047)$ & $-.01(.927)$ & $.34(.019)$ & $.14(.509)$ & $.30(.081)$ \\
\hline Roommate-Comp. & $.00(.982)$ & $.10(.493)$ & $.20(.185)$ & $-.22(.143)$ & $.11(.454)$ & $.38(.008)$ & $.38(.056)$ & $.20(.263)$ \\
\hline
\end{tabular}

Note: "Comp." = Compared to Usual. For Spouse Quality: $n=279$. For Children Quality: $n=132$. For Family Quality: $n=143$.

For In-Laws Quality: $n=18$. For Roommate Quality: $n=46-47$. For Other: $n=35$.

For all types of cohabitants, days in quarantine and days in social distancing were positively associated with relationship quality, both concurrently and compared to usual. That is, the longer people had been quarantining or social distancing, the higher quality their relationship with the people who live with them. There were some negative effects between magnitude of social distancing behavior and relationship with children compared to usual. The low sample size for participants living alone $(n=31)$ did not allow us to test the differences between those living alone and those living with others. 
We first examined the correlations between each Big Five dimension and each measure of psychological wellness. See Table 4 for correlations.

\section{Table 4}

Big Five Correlations with Daily Affect and Life Satisfaction

\begin{tabular}{|c|c|c|c|c|c|}
\hline & $\mathrm{X}$ & $\mathrm{A}$ & $\mathrm{C}$ & $\mathrm{N}$ & $\mathrm{O}$ \\
\hline & $\mathrm{r}(\mathrm{p})$ & $\mathrm{r}(\mathrm{p})$ & $\mathrm{r}(\mathrm{p})$ & $\mathrm{r}(\mathrm{p})$ & $\mathrm{r}(\mathrm{p})$ \\
\hline Positive Affect & $.05(.292)$ & $.14(.002)$ & $.13(.003)$ & $-.39(\mathrm{p}<.001)$ & $-.06(.157)$ \\
\hline Calm & $.00(.961)$ & $.14(.001)$ & $.08(.067)$ & $-.42(\mathrm{p}<.001)$ & $-.10(.021)$ \\
\hline Well-Being & $.04(.384)$ & $.09(.035)$ & $.11(.010)$ & $-.33(\mathrm{p}<.001)$ & $-.03(.451)$ \\
\hline Vigor & $.09(.046)$ & $.12(.007)$ & $.14(\mathrm{p}<.001)$ & $-.27(\mathrm{p}<.001)$ & $-.03(.558)$ \\
\hline Negative Affect & $-.08(.070)$ & $-.14(.001)$ & $-.20(\mathrm{p}<.001)$ & $.41(\mathrm{p}<.001)$ & $.18(\mathrm{p}<.001)$ \\
\hline Anger & $.05(.221)$ & $-.21(\mathrm{p}<.001)$ & $-.15(\mathrm{p}<.001)$ & $.24(\mathrm{p}<.001)$ & $.08(.076)$ \\
\hline Anxiety & $-.06(.145)$ & $-.11(.013)$ & $-.16(\mathrm{p}<.001)$ & $.43(\mathrm{p}<.001)$ & $.20(\mathrm{p}<.001)$ \\
\hline Depression & $-.10(.030)$ & $-.11(.015)$ & $-.17(\mathrm{p}<.001)$ & $.36(\mathrm{p}<.001)$ & $.17(\mathrm{p}<.001)$ \\
\hline Fatigue & $-.15(\mathrm{p}<.001)$ & $-.07(.128)$ & $-.19(\mathrm{p}<.001)$ & $.32(\mathrm{p}<.001)$ & $.14(.002)$ \\
\hline Life Satisfaction & $.19(\mathrm{p}<.001)$ & $.19(\mathrm{p}<.001)$ & $.29(\mathrm{p}<.001)$ & $-.38(\mathrm{p}<.001)$ & $-.10(.021)$ \\
\hline
\end{tabular}

Note: $\mathrm{n}$ ranges between 511 and 516 .

Then we performed linear regressions to examine moderation effects. We found personality moderators on the association between degree of social distancing and psychological wellness, particularly extraversion, conscientiousness, and neuroticism. These are displayed in Tables 5, 6, and 7 . 
Table 5

Linear Regressions for Psychological Wellness and Relationship Quality Predicted by Days in Quarantine, Moderated by Personality

\begin{tabular}{|c|c|c|c|c|c|}
\hline IV & DV & Intercept $b$ & Personality $b$ & $\begin{array}{c}\text { Days In } \\
\text { Quarantine } b\end{array}$ & Interaction $b$ \\
\hline \multirow{13}{*}{$\mathrm{X}$} & Positive Affect & $-.01(.879)$ & $.05(.401)$ & $.02(.707)$ & $.16(.013)$ \\
\hline & Negative Affect & $.08(.163)$ & $-.06(.279)$ & $-.04(.471)$ & $-.05(.365)$ \\
\hline & Life Satisfaction & $.01(.889)$ & $.19(.001)$ & $-.07(.240)$ & $.04(.495)$ \\
\hline & Spouse & $.04(.650)$ & $.08(.359)$ & $-.01(.937)$ & $.07(.545)$ \\
\hline & Spouse-Comp. & $.18(.061)$ & $-.09(.334)$ & $.27(.009)$ & $-.15(.212)$ \\
\hline & Children & $.11(.369)$ & $-.15(.277)$ & $.17(.204)$ & $.12(.463)$ \\
\hline & Children-Comp. & $.08(.549)$ & $-.11(.437)$ & $.11(.396)$ & $.10(.568)$ \\
\hline & Family & $-.04(.755)$ & $.04(.715)$ & $.24(.021)$ & $.05(.626)$ \\
\hline & Family - Comp. & $.04(.707)$ & $.26(.037)$ & $.17(.102)$ & $-.02(.852)$ \\
\hline & In-Laws & $.09(.777)$ & $-.26(.696)$ & $.48(.244)$ & $-.49(.499)$ \\
\hline & In-Laws - Comp. & $.05(.882)$ & $-.43(.568)$ & $.30(.504)$ & $-.46(.577)$ \\
\hline & Roommate & $.05(.835)$ & $.01(.976)$ & $.31(.317)$ & $-.28(.452)$ \\
\hline & Roommate - Comp. & $.36(.105)$ & $.15(.593)$ & $.58(.053)$ & $-.15(.660)$ \\
\hline \multirow{13}{*}{ A } & Positive Affect & $-.02(.704)$ & $.13(.020)$ & $.02(.698)$ & $.04(.443)$ \\
\hline & Negative Affect & $.09(.109)$ & $-.13(.014)$ & $-.04(.437)$ & $.01(.876)$ \\
\hline & Life Satisfaction & $-.01(.880)$ & $.20(\mathrm{p}<.001)$ & $-.06(.286)$ & $.04(.438)$ \\
\hline & Spouse & $.04(.624)$ & $.20(.032)$ & $-.01(.887)$ & $.11(.218)$ \\
\hline & Spouse - Comp. & $.08(.385)$ & $.31(.002)$ & $.12(.172)$ & $.26(.009)$ \\
\hline & Children & $.12(.323)$ & $.11(.439)$ & $.14(.269)$ & $.23(.120)$ \\
\hline & Children-Comp. & $.08(.498)$ & $.15(.315)$ & $.08(.514)$ & $.12(.432)$ \\
\hline & Family & $-.07(.533)$ & $.21(.030)$ & $.27(.004)$ & $.08(.400)$ \\
\hline & Family - Comp. & $-.04(.724)$ & $.09(.362)$ & $.20(.056)$ & $.07(.511)$ \\
\hline & In-Laws & $.04(.921)$ & $.13(.781)$ & $.27(.544)$ & $.35(.489)$ \\
\hline & In-Laws - Comp. & $-.02(.950)$ & $.30(.538)$ & $.00(.999)$ & $.60(.284)$ \\
\hline & Roommate & $.16(.569)$ & $.03(.878)$ & $.18(.594)$ & $-.09(.699)$ \\
\hline & Roommate - Comp. & $.42(.118)$ & $.01(.976)$ & $.46(.142)$ & $-.04(.863)$ \\
\hline \multirow{13}{*}{$\mathrm{C}$} & Positive Affect & $-.03(.649)$ & $.12(.049)$ & $.00(.946)$ & $-.11(.052)$ \\
\hline & Negative Affect & $.09(.100)$ & $-.15(.007)$ & $-.03(.597)$ & $.12(.026)$ \\
\hline & Life Satisfaction & $-.00(.988)$ & $.27(\mathrm{p}<.001)$ & $-.07(.232)$ & $-.09(.101)$ \\
\hline & Spouse & $.05(.516)$ & $.05(.504)$ & $.02(.781)$ & $-.10(.186)$ \\
\hline & Spouse - Comp. & $.12(.187)$ & $.04(.674)$ & $.20(.028)$ & $-.09(.280)$ \\
\hline & Children & $.09(.470)$ & $.09(.539)$ & $.09(.531)$ & $.19(.202)$ \\
\hline & Children-Comp. & $.10(.447)$ & $-.01(.957)$ & $.09(.491)$ & $.01(.956)$ \\
\hline & Family & $-.03(.753)$ & $.08(.471)$ & $.21(.027)$ & $.00(.962)$ \\
\hline & Family - Comp. & $-.03(.771)$ & $.05(.641)$ & $.13(.188)$ & $-.11(.236)$ \\
\hline & In-Laws & $.11(.672)$ & $-.69(.088)$ & $.22(.542)$ & $.57(.169)$ \\
\hline & In-Laws - Comp. & $.06(.868)$ & $-.15(.773)$ & $.10(.835)$ & $.17(.756)$ \\
\hline & Roommate & $.11(.656)$ & $.06(.749)$ & $.01(.962)$ & $-.23(.278)$ \\
\hline & Roommate - Comp. & $.52(.018)$ & $.31(.070)$ & $.44(.089)$ & $-.04(.827)$ \\
\hline
\end{tabular}

\begin{tabular}{|c|c|c|c|c|c|}
\hline IV & DV & Intercept $b$ & Personality $b$ & $\begin{array}{c}\text { Days In } \\
\text { Quarantine } \boldsymbol{b}\end{array}$ & $\begin{array}{c}\text { Interaction } \\
b\end{array}$ \\
\hline \multirow{13}{*}{$\mathrm{N}$} & Positive Affect & $-.03(.601)$ & $-.41(\mathrm{p}<.001)$ & $.07(.210)$ & $.06(.284)$ \\
\hline & Negative Affect & $.10(.059)$ & $.40(\mathrm{p}<.001)$ & $-.10(.068)$ & $-.10(.071)$ \\
\hline & Life Satisfaction & $-.02(.763)$ & $-.35(\mathrm{p}<.001)$ & $-.03(.647)$ & $.09(.106)$ \\
\hline & Spouse & $.06(.433)$ & $-.17(.036)$ & $.05(.557)$ & $-.04(.628)$ \\
\hline & Spouse-Comp. & $.12(.173)$ & $-.21(.017)$ & $.24(.010)$ & $-.02(.809)$ \\
\hline & Children & $.13(.300)$ & $-.18(.177)$ & $.15(.251)$ & $-.04(.777)$ \\
\hline & Children-Comp. & $.10(.408)$ & $.00(.974)$ & $.08(.535)$ & $-.05(.741)$ \\
\hline & Family & $.04(.690)$ & $-.44(p<.001)$ & $.21(.015)$ & $.10(.280)$ \\
\hline & Family - Comp. & $.00(.980)$ & $-.18(.122)$ & $.17(.076)$ & $.00(.997)$ \\
\hline & In-Laws & $-.18(.611)$ & $.58(.247)$ & $.64(.178)$ & $-.58(.223)$ \\
\hline & In-Laws - Comp. & $.00(.995)$ & $.10(.866)$ & $.22(.701)$ & $-.17(.768)$ \\
\hline & Roommate & $.08(.714)$ & $-.23(.313)$ & $.17(.504)$ & $.06(.863)$ \\
\hline & Roommate - Comp. & $.38(.065)$ & $-.28(.170)$ & $.47(.047)$ & $-.16(.569)$ \\
\hline \multirow{13}{*}{$\mathrm{O}$} & $\begin{array}{l}\text { Positive Affect } \\
\end{array}$ & $-.03(.668)$ & $-.06(.321)$ & $.02(.785)$ & $.08(.180)$ \\
\hline & Negative Affect & $.08(.138)$ & $.13(.022)$ & $-.04(.436)$ & $-.04(.514)$ \\
\hline & Life Satisfaction & $-.00(.996)$ & $-.14(.019)$ & $-.07(.261)$ & $-.04(.455)$ \\
\hline & Spouse & $.08(.292)$ & $.16(.044)$ & $.06(.435)$ & $.12(.122)$ \\
\hline & Spouse - Comp. & $.13(.141)$ & $-.02(.841)$ & $.20(.028)$ & $.00(.974)$ \\
\hline & Children & $.15(.236)$ & $-.04(.732)$ & $.16(.221)$ & $.08(.525)$ \\
\hline & Children - Comp. & $.10(.398)$ & $-.12(.314)$ & $.12(.352)$ & $.10(.423)$ \\
\hline & Family & $-.05(.653)$ & $-.12(.242)$ & $.22(.019)$ & $-.03(.727)$ \\
\hline & Family - Comp. & $-.05(.677)$ & $.01(.960)$ & $.18(.070)$ & $-.09(.406)$ \\
\hline & In-Laws & $.07(.801)$ & $-.33(.203)$ & $1.02(.193)$ & $-.49(.413)$ \\
\hline & In-Laws - Comp. & $.02(.950)$ & $.15(.629)$ & $-.35(.714)$ & $.37(.621)$ \\
\hline & Roommate & $.14(.557)$ & $-.23(.446)$ & $.17(.496)$ & $-.17(.638)$ \\
\hline & Roommate - Comp. & $.37(.094)$ & $.13(.650)$ & $.45(.066)$ & $-.05(.892)$ \\
\hline
\end{tabular}

Note: IV = Independent Personality Variable. DV = Dependent Variable. Personality $b=$ Main effect of IV. Days In Quarantine $b=$ Main effect of Days In Quarantine. Interaction $b=$ Interaction between Personality and Days in Quarantine. Bold labels are psychological wellness variables. Non-bold labels are relationship quality variables. "Comp." = Compared to Usual. All variables standardized prior to analyses. 
Table 6

Linear Regressions for Psychological Wellness and Relationship Quality Predicted by Days in Social Distancing, Moderated by Personality

\begin{tabular}{|c|c|c|c|c|c|}
\hline IV & DV & Intercept $b$ & Personality $b$ & $\begin{array}{l}\text { Days In Social } \\
\text { Dist. } b\end{array}$ & Interaction $b$ \\
\hline \multirow{13}{*}{$\mathrm{X}$} & Positive Affect & $-.01(.870)$ & $.06(.226)$ & $-.02(.763)$ & $.06(.296)$ \\
\hline & Negative Affect & $.01(.798)$ & $-.08(.091)$ & $-.07(.134)$ & $-.04(.436)$ \\
\hline & Life Satisfaction & $.02(.739)$ & $.20(.001)$ & $.01(.880)$ & $.05(.310)$ \\
\hline & Spouse & $.00(.992)$ & $.00(.999)$ & $.04(.547)$ & $-.02(.753)$ \\
\hline & Spouse-Comp. & $.07(.316)$ & $-.05(.484)$ & $.10(.181)$ & $-.05(.488)$ \\
\hline & Children & $.02(.837)$ & $-.22(.037)$ & $.22(.045)$ & $-.10(.315)$ \\
\hline & Children - Comp. & $.08(.460)$ & $-.17(.113)$ & $.30(.010)$ & $.01(.961)$ \\
\hline & Family & $.08(.463)$ & $.07(.560)$ & $.14(.195)$ & $.05(.641)$ \\
\hline & Family - Comp. & $.08(.482)$ & $.07(.578)$ & $.15(.179)$ & $.08(.463)$ \\
\hline & In-Laws & $-.10(.704)$ & $-.47(.218)$ & $.31(.326)$ & $.07(.868)$ \\
\hline & In-Laws - Comp. & $-.03(.910)$ & $-.67(.072)$ & $.42(.176)$ & $-.19(.628)$ \\
\hline & Roommate & $-.09(.626)$ & $-.05(.828)$ & $.30(.088)$ & $-.28(.352)$ \\
\hline & Roommate - Comp. & $.14(.435)$ & $.15(.516)$ & $.19(.265)$ & $.17(.544)$ \\
\hline \multirow{13}{*}{ A } & Positive Affect & $-.01(.780)$ & $.18(\mathrm{p}<.001)$ & $-.01(.865)$ & $.07(.222)$ \\
\hline & Negative Affect & $.02(.664)$ & $-.19(\mathrm{p}<.001)$ & $-.08(.111)$ & $-.02(.705)$ \\
\hline & Life Satisfaction & $-.00(.954)$ & $.18(\mathrm{p}<.001)$ & $.02(.761)$ & $.09(.084)$ \\
\hline & Spouse & $-.01(.916)$ & $.27(\mathrm{p}<.001)$ & $.04(.578)$ & $.11(.179)$ \\
\hline & Spouse - Comp. & $.06(.416)$ & $.22(.009)$ & $.08(.230)$ & $.18(.033)$ \\
\hline & Children & $-.01(.957)$ & $.27(.052)$ & $.19(.070)$ & $.13(.393)$ \\
\hline & Children - Comp. & $.08(.456)$ & $.14(.331)$ & $.30(.010)$ & $.17(.300)$ \\
\hline & Family & .05 (.609) & $.22(.023)$ & $.12(.212)$ & $-.01(.887)$ \\
\hline & Family - Comp. & $.05(.598)$ & $.11(.269)$ & $.11(.247)$ & $.05(.575)$ \\
\hline & In-Laws & $.01(.959)$ & $-.21(.529)$ & $.09(.757)$ & $.53(.143)$ \\
\hline & In-Laws - Comp. & $.02(.930)$ & $-.10(.770)$ & $.14(.665)$ & $.50(.188)$ \\
\hline & Roommate & $-.06(.739)$ & $-.07(.634)$ & $.32(.069)$ & $.11(.442)$ \\
\hline & Roommate - Comp. & $.12(.490)$ & $-.14(.323)$ & $.19(.245)$ & $.00(.977)$ \\
\hline \multirow{13}{*}{$\mathrm{C}$} & Positive Affect & $-.02(.723)$ & $.11(.031)$ & $-.02(.729)$ & $-.06(.151)$ \\
\hline & Negative Affect & $.03(.583)$ & $-.21(\mathrm{p}<.001)$ & $-.07(.154)$ & $.06(.190)$ \\
\hline & Life Satisfaction & $-.01(.830)$ & $.27(\mathrm{p}<.001)$ & $-.00(.975)$ & $-.04(.421)$ \\
\hline & Spouse & $-.01(.880)$ & $.07(.304)$ & $.06(.411)$ & $-.09(.143)$ \\
\hline & Spouse - Comp. & $.06(.404)$ & $.03(.665)$ & $.11(.151)$ & $-.09(.184)$ \\
\hline & Children & $-.03(.782)$ & $.09(.481)$ & $.19(.134)$ & $-.10(.440)$ \\
\hline & Children - Comp. & $.11(.403)$ & $-.03(.804)$ & $.34(.012)$ & $-.13(.325)$ \\
\hline & Family & $.04(.690)$ & $-.01(.934)$ & $.12(.283)$ & $.02(.877)$ \\
\hline & Family - Comp. & $.02(.888)$ & $-.09(.450)$ & $.09(.422)$ & $-.02(.817)$ \\
\hline & In-Laws & $-.08(.767)$ & $-.27(.491)$ & $.15(.660)$ & $-.01(.982)$ \\
\hline & In-Laws - Comp. & $-.04(.884)$ & $.09(.829)$ & $.29(.419)$ & $-.11(.785)$ \\
\hline & Roommate & $.03(.855)$ & $.09(.577)$ & $.20(.238)$ & $-.30(.127)$ \\
\hline & Roommate - Comp. & $.17(.346)$ & $.05(.779)$ & $.12(.485)$ & $-.21(.270)$ \\
\hline
\end{tabular}

\begin{tabular}{|c|c|c|c|c|c|}
\hline IV & DV & Intercept $b$ & Personality $b$ & $\begin{array}{c}\text { Days in } \\
\text { Social Dist. } b\end{array}$ & Interaction $b$ \\
\hline \multirow{13}{*}{$\mathrm{N}$} & Positive Affect & $-.01(.823)$ & $-.36(\mathrm{p}<.001)$ & $.00(.980)$ & $.08(.115)$ \\
\hline & Negative Affect & $.01(.784)$ & $.42(\mathrm{p}<.001)$ & $-.09(.037)$ & $-.03(.558)$ \\
\hline & Life Satisfaction & $.00(.922)$ & $-.40(\mathrm{p}<.001)$ & $.03(.590)$ & $.05(.320)$ \\
\hline & Spouse & $.00(.956)$ & $-.19(.009)$ & $.04(.552)$ & $-.09(.265)$ \\
\hline & Spouse-Comp. & $.07(.354)$ & $-.08(.299)$ & $.08(.286)$ & $-.13(.109)$ \\
\hline & Children & $-.03(.776)$ & $-.09(.453)$ & $.17(.107)$ & $.10(.462)$ \\
\hline & Children-Comp. & $.06(.571)$ & $-.02(.851)$ & $.26(.022)$ & $-.07(.597)$ \\
\hline & Family & $.17(.071)$ & $-.47(\mathrm{p}<.001)$ & $.13(.169)$ & $.08(.397)$ \\
\hline & Family - Comp. & $.07(.496)$ & $-.09(.411)$ & $.12(.241)$ & $-.03(.807)$ \\
\hline & In-Laws & $.00(.991)$ & $-.31(.433)$ & $.26(.452)$ & $.28(.434)$ \\
\hline & In-Laws - Comp. & $.05(.867)$ & $-.30(.458)$ & $.30(.393)$ & $.22(.542)$ \\
\hline & Roommate & $-.09(.606)$ & $-.24(.200)$ & $.28(.106)$ & $-.15(.494)$ \\
\hline & Roommate - Comp. & $.10(.569)$ & $-.19(.280)$ & $.15(.351)$ & $-.03(.885)$ \\
\hline \multirow{13}{*}{$\mathrm{O}$} & Positive Affect & $-.02(.743)$ & $-.05(.371)$ & $-.01(.848)$ & $.03(.576)$ \\
\hline & Negative Affect & $.02(.746)$ & $.16(.002)$ & $-.08(.102)$ & $.01(.898)$ \\
\hline & Life Satisfaction & $.00(.994)$ & $-.14(.008)$ & $.02(.759)$ & $.02(.671)$ \\
\hline & Spouse & $.00(.970)$ & $.09(.188)$ & $.03(.640)$ & $.00(.994)$ \\
\hline & Spouse-Comp. & $.06(.380)$ & $.02(.832)$ & $.07(.333)$ & $-.03(.681)$ \\
\hline & Children & $-.02(.863)$ & $-.03(.764)$ & $.22(.074)$ & $.10(.318)$ \\
\hline & Children - Comp. & $.07(.560)$ & $-.05(.676)$ & $.32(.011)$ & $.10(.329)$ \\
\hline & Family & $.06(.565)$ & $-.07(.510)$ & $.10(.285)$ & $.04(.682)$ \\
\hline & Family - Comp. & $.03(.764)$ & $.08(.418)$ & $.12(.219)$ & $-.10(.333)$ \\
\hline & In-Laws & $-.01(.964)$ & $.05(.844)$ & $.56(.264)$ & $-.43(.387)$ \\
\hline & In-Laws - Comp. & $.01(.981)$ & $.25(.368)$ & $.44(.389)$ & $-.30(.546)$ \\
\hline & Roommate & $-.05(.795)$ & $.07(.741)$ & $.31(.089)$ & $-.11(.613)$ \\
\hline & Roommate - Comp. & $.18(.287)$ & $.00(.992)$ & $.27(.088)$ & $-.46(.028)$ \\
\hline
\end{tabular}

Note: IV = Independent Personality Variable. DV = Dependent Variable. Personality = Main effect of IV Days in Social Distancing = Main effect of Days in Social Distancing. Interaction $=$ Interaction between Personality and Days in Social Distancing. Bold labels are psychological wellness variables. Non-bold labels are relationship quality variables. "Comp." = Compared to Usual. 
Table 7

Linear Regressions for Psychological Wellness and Relationship Quality Predicted by Magnitude of Social Distancing Behavior, Moderated by Personality

\begin{tabular}{|c|c|c|c|c|c|}
\hline IV & DV & Intercept & Personality & $\begin{array}{c}\text { Degree of } \\
\text { Social Dist. }\end{array}$ & Interaction \\
\hline \multirow{13}{*}{$\mathrm{X}$} & Positive Affect & $.00(.953)$ & $.05(.278)$ & $-.10(.020)$ & $.04(.419)$ \\
\hline & Negative Affect & $.00(.968)$ & $-.08(.067)$ & $.05(.218)$ & $-.03(.496)$ \\
\hline & Life Satisfaction & $.00(.920)$ & $.19(\mathrm{p}<.001)$ & $.02(.583)$ & $.01(.822)$ \\
\hline & Spouse & $-.01(.847)$ & $.01(.906)$ & $.13(.023)$ & $.14(.022)$ \\
\hline & Spouse-Comp. & $.01(.929)$ & $-.05(.386)$ & $.06(.300)$ & $.06(.344)$ \\
\hline & Children & $.04(.689)$ & $-.15(.078)$ & $-.07(.423)$ & $.12(.159)$ \\
\hline & Children-Comp. & $.04(.659)$ & $-.15(.079)$ & $-.23(.004)$ & $.13(.120)$ \\
\hline & Family & $.02(.870)$ & $.02(.839)$ & $.03(.775)$ & $-.01(.919)$ \\
\hline & Family - Comp. & $.04(.656)$ & $.15(.132)$ & $.00(.984)$ & $.15(.107)$ \\
\hline & In-Laws & $-.07(.792)$ & $-.01(.978)$ & $-.20(.350)$ & $.24(.423)$ \\
\hline & In-Laws - Comp. & $.01(.967)$ & $-.39(.235)$ & $-.07(.744)$ & $-.04(.901)$ \\
\hline & Roommate & $.07(.649)$ & $-.06(.773)$ & $.33(.025)$ & $.05(.771)$ \\
\hline & Roommate-Comp. & $.08(.579)$ & $.00(.998)$ & $.38(.009)$ & $-.03(.849)$ \\
\hline \multirow{13}{*}{ A } & Positive Affect & $.00(.951)$ & $.14(.002)$ & $-.11(.014)$ & $.00(.962)$ \\
\hline & Negative Affect & $.00(.999)$ & $-.15(\mathrm{p}<.001)$ & $.05(.216)$ & $-.04(.358)$ \\
\hline & Life Satisfaction & $.00(.997)$ & $.19(\mathrm{p}<.001)$ & $.03(.509)$ & $.08(.036)$ \\
\hline & Spouse & $-.02(.682)$ & $.16(.012)$ & $.15(.008)$ & $.09(.088)$ \\
\hline & Spouse-Comp. & $-.01(.839)$ & $.12(.049)$ & $.08(.182)$ & $.09(.103)$ \\
\hline & Children & $.01(.895)$ & $.15(.109)$ & $-.04(.637)$ & $.00(.973)$ \\
\hline & Children-Comp. & $.00(.969)$ & $.13(.175)$ & $-.18(.034)$ & $.04(.599)$ \\
\hline & Family & $.04(.624)$ & $.19(.020)$ & $.05(.588)$ & $.21(.009)$ \\
\hline & Family - Comp. & $.01(.914)$ & $.06(.464)$ & $-.02(.826)$ & $.09(.287)$ \\
\hline & In-Laws & $.05(.846)$ & $-.50(.147)$ & $-.20(.336)$ & $-.24(.327)$ \\
\hline & In-Laws - Comp. & $.02(.935)$ & $-.19(.614)$ & $-.08(.716)$ & $.00(.988)$ \\
\hline & Roommate & $.07(.624)$ & $.03(.771)$ & $.35(.018)$ & $-.07(.531)$ \\
\hline & Roommate - Comp. & $.08(.556)$ & $.05(.667)$ & $.41(.005)$ & $-.11(.276)$ \\
\hline \multirow{13}{*}{$\mathrm{C}$} & Positive Affect & $.01(.763)$ & $.15(\mathrm{p}<.001)$ & $-.12(.009)$ & $-.11(.027)$ \\
\hline & Negative Affect & $-.01(.786)$ & $-.22(\mathrm{p}<.001)$ & $.07(.104)$ & $.13(.008)$ \\
\hline & Life Satisfaction & $.01(.847)$ & $.29(\mathrm{p}<.001)$ & $.00(.918)$ & $-.06(.176)$ \\
\hline & Spouse & $-.03(.606)$ & $.05(.474)$ & $.13(.028)$ & $.06(.361)$ \\
\hline & Spouse-Comp. & $-.02(.781)$ & $.05(.465)$ & $.07(.234)$ & $-.01(.840)$ \\
\hline & Children & $-.03(.721)$ & $.18(.082)$ & $-.01(.904)$ & $-.13(.238)$ \\
\hline & Children-Comp. & $-.01(.881)$ & $.18(.079)$ & $-.15(.059)$ & $-.27(.012)$ \\
\hline & Family & $.04(.656)$ & $.01(.889)$ & $-.01(.948)$ & $-.20(.093)$ \\
\hline & Family - Comp. & $-.01(.880)$ & $-.02(.861)$ & $-.02(.851)$ & $.02(.897)$ \\
\hline & In-Laws & $-.11(.667)$ & $-.35(.275)$ & $-.21(.315)$ & $.03(.914)$ \\
\hline & In-Laws - Comp. & $-.03(.900)$ & $-.03(.926)$ & $-.09(.706)$ & $.06(.862)$ \\
\hline & Roommate & $.16(.304)$ & $.11(.417)$ & $.25(.102)$ & $-.19(.219)$ \\
\hline & Roommate - Comp. & $.15(.346)$ & $.11(.425)$ & $.32(.035)$ & $-.10(.500)$ \\
\hline
\end{tabular}

\begin{tabular}{|c|c|c|c|c|c|}
\hline IV & DV & Intercept & Personality & $\begin{array}{l}\text { Degree of } \\
\text { Social Dist. }\end{array}$ & Interaction \\
\hline \multirow{13}{*}{$\mathrm{N}$} & Positive Affect & $.00(.970)$ & $-.39(\mathrm{p}<.001)$ & $-.10(.017)$ & $-.02(.628)$ \\
\hline & Negative Affect & $.00(.977)$ & $.41(\mathrm{p}<.001)$ & $.05(.249)$ & $.01(.877)$ \\
\hline & Life Satisfaction & $-.00(.998)$ & $-.38(\mathrm{p}<.001)$ & $.03(.432)$ & $.05(.287)$ \\
\hline & Spouse & $-.03(.671)$ & $-.13(.025)$ & $.15(.009)$ & $-.09(.124)$ \\
\hline & Spouse-Comp. & $-.01(.926)$ & $-.05(.418)$ & $.07(.235)$ & $-.09(.127)$ \\
\hline & Children & $.01(.909)$ & $-.16(.072)$ & $-.01(.881)$ & $-.23(.021)$ \\
\hline & Children-Comp. & $.02(.846)$ & $-.05(.621)$ & $-.19(.018)$ & $-.16(.103)$ \\
\hline & Family & $.11(.202)$ & $-.38(\mathrm{p}<.001)$ & $.04(.651)$ & $-.01(.910)$ \\
\hline & Family - Comp. & $.02(.800)$ & $-.12(.219)$ & $-.02(.849)$ & $-.05(.593)$ \\
\hline & In-Laws & $.00(.987)$ & $-.14(.641)$ & $-.27(.247)$ & $.22(.562)$ \\
\hline & In-Laws - Comp. & $.00(.991)$ & $-.08(.796)$ & $-.03(.892)$ & $-.20(.606)$ \\
\hline & Roommate & $.04(.752)$ & $-.28(.063)$ & $.33(.019)$ & $.11(.492)$ \\
\hline & Roommate - Comp. & $.05(.719)$ & $-.23(.130)$ & $.36(.010)$ & $-.11(.499)$ \\
\hline \multirow{13}{*}{$\mathrm{O}$} & Positive Affect & $.01(.864)$ & $-.05(.213)$ & $-.11(.013)$ & $-.07(.094)$ \\
\hline & Negative Affect & $.00(.956)$ & $.18(\mathrm{p}<.001)$ & $.04(.337)$ & $.02(.631)$ \\
\hline & Life Satisfaction & $-.00(.994)$ & $-.10(.018)$ & $.04(.423)$ & $.01(.779)$ \\
\hline & Spouse & $-.01(.887)$ & $.08(.206)$ & $.13(.033)$ & $-.05(.387)$ \\
\hline & Spouse - Comp. & $-.01(.895)$ & $-.03(.631)$ & $.07(.247)$ & $-.01(.805)$ \\
\hline & Children & $-.05(.616)$ & $-.06(.525)$ & $.06(.554)$ & $.10(.265)$ \\
\hline & Children-Comp. & $-.05(.620)$ & $-.05(.575)$ & $-.11(.292)$ & $.11(.231)$ \\
\hline & Family & $.05(.594)$ & $-.14(.083)$ & $.04(.690)$ & $-.16(.079)$ \\
\hline & Family-Comp. & $.01(.919)$ & $-.07(.424)$ & $-.01(.880)$ & $-.04(.647)$ \\
\hline & In-Laws & $-.08(.768)$ & $-.06(.809)$ & $-.26(.249)$ & $-.14(.506)$ \\
\hline & In-Laws - Comp. & $-.03(.909)$ & $.22(.384)$ & $-.08(.717)$ & $.01(.960)$ \\
\hline & Roommate & $.08(.571)$ & $-.09(.624)$ & $.35(.019)$ & $-.09(.642)$ \\
\hline & Roommate - Comp. & $.10(.461)$ & $.02(.892)$ & $.39(.007)$ & $-.29(.102)$ \\
\hline
\end{tabular}

Note: IV $=$ Independent Personality Variable. DV $=$ Dependent Variable. Personality $=$ Main effect of IV. Days In Quarantine = Main effect of Days In Quarantine. Interaction = Interaction between Personality and Days in Quarantine. Bold labels are psychological wellness variables. Non-bold labels are relationship quality variables. "Comp." = Compared to Usual. 
While the strongest effects were found for days in quarantine, the directional trends were similar for days in social distancing and magnitude of social distancing behavior. The findings are partially surprising. Whereas we predicted that those higher in extraversion and conscientiousness would struggle in quarantine, and that those higher in neuroticism would thrive, we found the opposite effects for extraversion. In terms of relationship quality with cohabitants, the strongest interactive effects were found for agreeableness. That is, as degree of social distancing increased, those lower in agreeableness report lower relationship quality, and those higher in agreeableness report higher relationship quality, particularly for relationships with spouses and children. Interactive effects for relationship quality among other family members, in-laws, or roommates should be interpreted with caution, as the sample size for people who were cohabiting with those types was already quite small. We consider implications for all interactions in the Discussion.

\section{Discussion}

\section{Question 1: Does personality affect social distancing behavior?}

Consistent with our hypotheses, we found that extraversion was negatively associated with degree of social distancing, and agreeableness, conscientiousness, and neuroticism were positively related to degree of social distancing. We reason that high scores on agreeableness and conscientiousness are likely more associated with compliance with government regulations or medical advice, and that high scores on neuroticism are likely more disease- and risk-avoidant, thus staying isolated to avoid exposure. We also reason that high scores on extraversion equate to higher need for social engagement. While effect sizes are small for extraversion, and while most 
people appear to generally comply with government regulations, more extraverted individuals still appear to have the need for social connection that may be restricted during the pandemic.

Extraversion and conscientiousness are also highly related to more online social activities, demonstrating that those higher in extraversion and conscientiousness find ways to connect despite physical limitations. Thus, extraverted and conscientious individuals could benefit from being directed to more online activities to socially connect and be productive.

\section{Question 2: How does the degree of social distancing affect psychological wellness and} relationship quality with cohabitants?

Higher degree of social distancing can hurt psychological wellness. Individuals who spend more time compared to others doing in-person social activities fare better in psychological wellness outcomes, but this has not always been possible during the pandemic. There is some evidence that online social activities, such as virtual chats with friends or family, contribute to positive affective outcomes. Therefore, even when people are unable to connect with others inperson, it appears that online connections provide a decent substitute to support psychological wellness. This could have adverse implications for those without access to reliable internet or networking platforms, as they will more likely be unable to maintain the social connectivity that contributes to psychological wellness.

In terms of relationship quality with cohabitants, results suggest that degree of social distancing is mostly beneficial to relationship quality, especially when compared to normal. Higher degree of social distancing may lead to greater opportunities for quality time and connection with cohabitants, specifically by limiting distractions from work and outside-thehome social interactions. It is important to note that these effects can only be generalized to the normal population of relationships, and we cannot speak to the impact of quarantine on 
relationships suffering from domestic abuse. Additionally, future work should examine whether cohabitation during a pandemic provides benefits compared to living alone.

\section{Question 3: Does personality moderate the association between degree of social distancing} and psychological wellness or relationship quality?

Whereas we predicted that those higher in extraversion would face worse psychological outcomes in social distancing, we found the opposite. Those higher in extraversion displayed higher positive affect and life satisfaction and lower negative affect as the degree of social distancing increased, and vice versa for low scorers. This effect is likely driven by the fact that those higher in extraversion find ways to connect with others, despite physical restrictions, and may be able to engage in more social interaction as remote socializing is normalized. Our data support this; when assessing daily activities normal to their daily routine, extraversion is positively correlated with online activities, including virtual chats and social media usage. Therefore, introverts are at higher risk for poor mental health outcomes as the degree of social distancing gets more extreme (perhaps because those beneficial social interactions are largely elective in social distancing).

As degree of social distancing increased, those higher in conscientiousness displayed lower positive affect and life satisfaction, and higher negative affect, and vice versa for low scorers. Conscientiousness typically correlates positively with psychological wellness. However, when interacting with degree of social distancing, this effect is reversed. We suspect that this effect has to do with the desire and ability to get work done. According to the results presented in Table 2, higher conscientious individuals seek opportunities to complete in-person tasks, but relative to their normal routine, they are performing fewer work tasks, such as running errands. On the other hand, lower conscientious individuals may not have the desire or motivation to get 
work done, and therefore should not mind physical limitations on work tasks. Therefore, high conscientious individuals are at higher risk for poor psychological outcomes as degree of social distancing increases.

As degree of social distancing increases, those higher in neuroticism displayed higher positive affect and life satisfaction and lower negative, and vice versa for low scorers. Higher neuroticism individuals typically display lower psychological wellness (see Table 4), but this effect is reversed by degree of social distancing. We suspect that the time in social distancing provides a sense of comfort and safety from any possible exposure to COVID-19 or other risks.

In terms of relationship quality with cohabitants, the strongest interactive effects were found for agreeableness. That is, as degree of social distancing increased, those lower in agreeableness displayed poorer relationship quality with cohabitants, particularly spouses and children. Generally, agreeableness is positively associated with relationship satisfaction, and degree of social distancing enhances this effect. We suspect that because social distancing allows for more opportunities for personal interaction, those lower on agreeableness will be more frustrated with their interaction partners, thus resulting in more divisive relationships. We also suspect that those low on agreeableness would be less likely to cooperate or assist other cohabitants who are struggling. So, given that relationship quality was assessed only from one perspective, we expect future studies to demonstrate that as degree of social distancing increases, the spouses and children of people who are low on agreeableness are affected adversely as well.

\section{Limitations}

During the time of the current study, most individuals were engaged in social distancing. While this was insightful for examining the effects of extreme levels of social distancing, future studies should examine these effects across a longer period of time, especially as governmental 
regulations fluctuate. Effect sizes for some of our results were small, so we focused mainly on overall trends rather than isolated singular effects. However, because so many of the trends were consistent across measurement methods, we expect that these effects will replicate in future studies and over longer periods of time.

\section{Conclusion}

Quarantine and social distancing in response to the COVID-19 pandemic has adverse implications for psychological wellness and positive implications for relationships with cohabitants. Online connections with others seem to mitigate the adverse effects. Those higher in agreeableness, conscientiousness, and neuroticism are more likely to engage in proper quarantine measures, while those high in extraversion are more likely to continue to participate in in-person social activities. Introverts, higher conscientious individuals, and lower neuroticism individuals tend to suffer more adverse outcomes the longer and more extreme the social distancing. Those lower in agreeableness report worse relationship outcomes with cohabitants the more extreme the social distancing.

Overall, the results of the current study offer important insights for how individuals differ in the way quarantine and social distancing impact their daily lives, relationships, and psychological wellness. 


\section{References}

Booth-Kewley, S., \& Vickers Jr, R. R. (1994). Associations between major domains of personality and health behavior. Journal of Personality, 62(3), 281-298.

Cacioppo, J. T., \& Cacioppo, S. (2014). Social relationships and health: The toxic effects of perceived social isolation. Social and Personality Psychology Compass, 8(2), 58-72.

Costa, P. T., \& McCrae, R. R. (1980). Influence of extraversion and neuroticism on subjective well-being: Happy and unhappy people. Journal of Personality and Social Psychology, 38(4), 668-678. https://doi.org/10.1037/0022-3514.38.4.668

Diener, E., Emmons, R. A., Larsen, R. J., \& Griffin, S. (1985). The Satisfaction with Life Scale. Journal of Personality Assessment, 49, 71-75.

Friedman, H. S., \& Booth-Kewley, S. (1987). The" disease-prone personality": A meta-analytic view of the construct. American Psychologist, 42(6), 539.

Goldberg, L. R. (1990). An alternative" description of personality": the big-five factor structure. Journal of Personality and Social Psychology, 59(6), 1216.

Imhoff, R., \& Lamberty, P. (2020). A bioweapon or a hoax? The link between distinct conspiracy beliefs about the Coronavirus disease (COVID-19) outbreak and pandemic behavior.

Holland, A. S., \& Roisman, G. I. (2008). Big Five personality traits and relationship quality: Self-reported, observational, and physiological evidence. Journal of Social and Personal Relationships, 25(5), 811-829.

Jones, A. B., Brown, N. A., Serfass, D. G., \& Sherman, R. A. (2017). Personality and density distributions of behavior, emotions, and situations. Journal of Research in Personality, 69, $225-236$. 
Kagel, J., \& McGee, P. (2014). Personality and cooperation in finitely repeated prisoner's dilemma games. Economics Letters, 124(2), 274-277.

Laboratory for the Study of Stress, Immunity, and Disease. (2016). Common Cold Project. Retrieved from http://www.commoncoldproject.com

Lyubomirsky, S. \& Lepper, H. S. (1999). A measure of subjective happiness: Preliminary reliability and construct validation. Social Indicators Research, 46, 137-155

Okabe-Miyamoto, K., Folk, D. P., Lyubomirsky, S., \& Dunn, E. W. (2020, June 24). Changes in Social Connection During COVID-19 Social Distancing: It's Not (Household) Size That Matters, It's Who You're With. https://doi.org/10.31234/osf.io/zdq6y

Rammstedt, B. \& John, O. P. (2007). Measuring personality in one minute or less: A 10-item short version of the Big Five Inventory in English and German. Journal of Research in Personality, 41, 203-212.

Sherman, R. A., Rauthmann, J. F., Brown, N. A., Serfass, D. S., \& Jones, A. B. (2015). The independent effects of personality and situations on real-time expressions of behavior and emotion. Journal of Personality and Social Psychology, 109(5), 872-888.

Schimmack, U., Oishi, S., Furr, R. M., \& Funder, D. C. (2004). Personality and life satisfaction: A facet-level analysis. Personality and Social Psychology Bulletin, 30(8), 1062-1075.

Qiu, J., Shen, B., Zhao, M., Wang, Z., Xie, B., \& Xu, Y. (2020). A nationwide survey of psychological distress among Chinese people in the COVID-19 epidemic: implications and policy recommendations. General Psychiatry, 33(2).

Zhang, J., Lu, H., Zeng, H., Zhang, S., Du, Q., Jiang, T., \& Du, B. (2020). The differential psychological distress of populations affected by the COVID-19 pandemic. Brain, Behavior, and Immunity. 
